\title{
The Markov Process as a Model of Migration Based on the Example of the Movement of Banknotes*
}

\begin{abstract}
Arkadiusz Manikowski*
This paper presents a way of using the Markov chain model for the analysis of migration based on the example of banknote migration between regions in Poland. We have presented the application of the methodology for estimating one-step transition probabilities for the Markov chain based on macro-data gathered during the project conducted in the National Bank of Poland (NBP) in the period of December 2015-2018. We have shown the usefulness of state-aggregated Markov chain not only as a model of banknote migration but as migration in general.

The banknotes are considered here as goods, so their migration is strictly related to, inter alia, the movement of people (commuting to work, business trips, etc.).Thus, the gravity-like properties of cash migration pointed to the gravity model as one of the most pervasive empirical models in regional science. Transition probability of the Markov chain expressing the attractive force between regions allows for estimating the gravity model for the identification of relevant reasons of note and, consequently, people migration.
\end{abstract}

Keywords: migration of people, migration of banknotes, Markov chain, gravity model.

Submitted:| Accepted:

\section{Proces Markowa jako model migracji na przykładzie przemieszczania się banknotów}

W artykule przedstawiono sposób wykorzystania tańcucha Markowa do analizy migracji na przyktadzie przemieszcza się banknotów między regionami w Polsce. Przedstawiono zastosowanie metodyki szacowania prawdopodobieństw przejścia dla tańcucha Markowa na podstawie makrodanych zebranych w ramach projektu realizowanego $w$ NBP w okresie od grudnia 2015 do końca 2018 roku. Wykazano przydatność zagregowanego w stanach tańcucha Markowa nie tylko jako modelu migracji banknotów, lecz także jako modelu migracji w ogóle. Banknoty traktowane sq tu jako towary, więc ich migracja jest ściśle zwiazana m.in. z przemieszczaniem się ludzi (dojazdy do pracy, podróże stużbowe itp.). Tak więc tzw. grawitacyjne wtaściwości migracji gotówki wskazały na model grawitacyjny Reilly'ego jako jeden z najbardziej rozpowszechnionych modeli empirycznych stosowanych w analizach regionalnych. Praw-

\footnotetext{
* This paper should not be reported as representing the views of the NBP or the University of Warsaw. The main thesis and results of the article were presented at the international cash conference Cash in the Age of Payment Diversity hosted by Deutsche Bundesbank on 11-12 September 2019. https://www.bundesbank.de/en/service/dates/cash-in-the-age-of-payment-diversity--763306.

** Arkadiusz Manikowski - PhD, Faculty of Management, University of Warsaw; Cash \& Issue Department, National Bank of Poland, https://orcid.org/0000-0002-2687-8757.

Correspondence address: Faculty of Management, University of Warsaw, 1/3 Szturmowa, 02-678 Warsaw, Poland; e-mail: amanikowski@wz.uw.edu.pl.
} 
dopodobieństwa przejść tańcucha Markowa wyrażających site przyciagania między regionami pozwolito na oszacowanie modelu grawitacyjnego w celu zidentyfikowania istotnych przyczyn migracji banknotów jak i ludności.

Słowa kluczowe: migracja ludności, migracja banknotów, łańcuch Markowa, model grawitacyjny.

JEL: E510, C600, J610

\section{Introduction}

The research and observations made by the author at the Cash and Issue Department, the National Bank of Poland (NBP), indicate that the main reasons for the migration of banknotes with low transactional denomination are as follows:

(1) daily commuting to work in another region,

(2) flow of tourists,

(3) business trip,

(4) networks of companies processing cash (such as CIT, post office),

(5) network of central bank branches,

(6) common road transport.

Therefore, the data on and the method of banknote migration can help analyze the daily migration of people due to commuting to work in another region, business trips, and due to tourism of people.

The support can be directed by the results of banknote migration research or indirectly by showing how some analytical tools used in banknote migration may be adopted for the analysis of people migration.

In this paper, we present the migration model of banknotes between regions in Poland. We focus on the 10-zloty lowdenomination banknote because of the available data, collected during the socalled Note Case project conducted in the NBP over the 3-year period up to 2018. The main objective of the project was strictly related to the effect of the extension of the life span of the banknotes as an effect of their varnishing. During the project, data on the location of banknotes were also gathered, which allowed us to conduct another study focused on migration. The lowest 10 -zloty denomination is mainly used in transaction payments, so the results obtained can support the analysis of people migration in Poland. Opposite to the lowest denomination, the highest denomination can be considered from the point of view of migration outside the country due to the hoarding function of such banknotes (see, for example, Schautzer 2006). It allows us to investigate the foreign demand for banknotes.

In the literature, we can find several studies on cash migration. The main articles with a short description are presented in Table 1.

Table 1. The main results of cash migration

\begin{tabular}{|l|l|}
\hline \multicolumn{1}{|c|}{ Sources } & \multicolumn{1}{c|}{ Short description } \\
\hline Grasland, Guérin, and Tostain (2002) & $\begin{array}{l}\text { Consideration of the effect of people's mobility. } \\
\text { The analysis was based on data collected during a series of representative } \\
\text { surveys conducted in France in 2002. }\end{array}$ \\
\hline Stoyan (2002) and Stoyan et al. (2004) & Focused on $€ 1$ coin migration. Project carried out in Germany. \\
\hline van Blokland et al., (2002) & Focused on note migration and conducted in the Netherlands and Belgium. \\
\hline Seitz, Stoyan, and Tödter (2009) & $\begin{array}{l}\text { A study of the migration of } € 1 \text { coins within the euro area. The authors used, } \\
\text { inter alia, a simple two-state Markov chain for the description of coin outflow } \\
\text { from Germany, using the example of } € 1 \text { denomination. }\end{array}$ \\
\hline Uhl (2020) & Focused on coin migration between Germany and other euro area countries. \\
\hline
\end{tabular}

Source: Own analysis. 
We can find only a few articles where the relation between banknotes and migration of people is considered. For example, Fischer (2014) investigated the scale of immigration and demand for large-denomination banknotes based on the example of CHF 1,000 banknotes in Switzerland. He used an econometric model that estimates the demand effect of immigrants relative to natives of a Swiss municipality on banknote orders in the same city.

In this paper, we discuss a finite-space, homogeneous first-order Markov chain for application to the migration of transaction notes. Estimated transitional probabilities were used in the gravity model to explain why notes migrate.

The paper is organized as follows. Section 2 presents a description of the data used in the analysis. Section 3 presents the theoretical framework of a migration model such as the Markov chain and the gravity model. The following Section 4 shows the main results. The last section offers some conclusions on the usefulness of the mathematical model of migration presented in general.

\section{Description of the Empirical Data Used in the Analysis}

The data used in the analysis presented here were gathered during the Note Case project (named later Project) as an internal department project that was conducted in the Cash \& Issue Department of the NBP for 3 years (December 2015 - 2018). During this period, data on 10-zloty notes such as, inter alia, locations across the country were also collected. Therefore, it was possible to investigate the issues on, among other, scales of migration of notes between regions in Poland. Within the framework of the project, 2.4 million notes with denomination of 10 zlotys and known serial numbers were introduced into circulation in two regions: Warsaw (region s6) and Poznań (region s4) - see Figure 1. The sample of test notes accounts for about $1.6 \%$ of all 10 -zloty notes in circulation.

During the project, micropanel data were collected weekly by BPS M7 sorter machines with the function of serial number reading (SNR).

For further analysis, we decided to aggregate the 16 voivodships into seven regions. For aggregation, the following criteria were adopted:

- structure of the supply network of NBP branches,

- network of sorting (notes returned to branches without a sorter machine are sorted by another one equipped with BPS M7),

- structure of test notes from the point of view of their origin sources.

The result of the region aggregation is shown in Figure 1. Their basic statistics are presented in the appendix: Tables A.1 and A.2.

Figure 1. Regions in Poland and their relation to voivodships

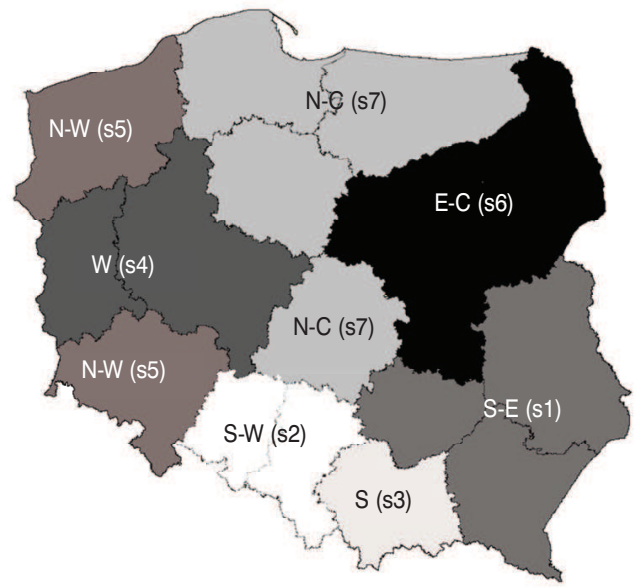

Source: Own calculation based on data collected by BPS M7 sorter machines. 
We can see three specific features of some regions which can disturb the memoryless property related to the movement of banknotes, which will be considered later:

- the large size of the 57 region, including four voivodships,

- the s5 region includes two non-neighboring voivodships,

- every region has at least two neighboring regions.

The neighborhood of several regions mentioned above and their composition may mean that the probability of a banknote passing to another region may depend on where the banknote came from. It can cause a loss of memoryless property. The issue of keeping the memoryless property will be considered later.

Based on the micro-data collected, we can estimate the number of fit notes $v_{i}(t)$ in the $i$-th region at time $t$ (considered later as macro-data):

$$
v_{i}(t)=\frac{a_{t i}}{f_{t i}} c_{t i}
$$

where $a_{t i}$ means the number of test notes returned to the Bank in the $i$-th region at time $t, f_{t i}$ - the number of all notes with the same denomination as the test notes returned to the Bank in the $i$-th region at $t$ time, $c_{t i}$ - the volume of notes in circulation in the $i$-th region at $t$ time.

Because the Project refers to transaction denomination ${ }^{1}$, it was acceptable and advisable to use the GDP of each region for $c_{t i}$ estimation, that is:

$$
c_{t i}=\% c_{t i} \cdot C
$$

with $\% c_{t i}=\% G D P_{t i}$ as a proportion of notes in circulation in the $i$-th region at $t$ time and $C$ as the number of notes in circulation in Poland.

We can also express $f_{t i}$ as:

$$
f_{t i}=\% f_{t i} \cdot F
$$

with $\% f_{t i}$ - the fraction of returned notes to the Bank in the $i$-th region (all with the same denomination), and $F$ - the number of notes returned to the Bank in the whole region.

Taking into account (1)-(3), we calculated (after some simple mathematical transformations) the proportion $k_{i}(t)$ of notes in every $i$-th region using the following formula:

$$
k_{i}(t)=\frac{a_{t i} \cdot \frac{\% c_{t i}}{\% f_{t i}}}{\sum_{j} a_{t j} \cdot \frac{\% c_{t j}}{\% f_{t j}}}
$$

According to equation (4), the number $a_{t i}$ of test notes returned to the Bank in the $i$-th region is corrected by the factor $\frac{\% c_{t i}}{\% f_{t i}}$.

The advantages of such an approach are as follows:

- If the fraction $\% f_{t i}$ of returned notes in $i$-region is the same as the fraction $\% c_{t i}$ of notes in circulation, then the proportion $k_{i}(t)$ is not dependent on the volume of notes in each region.

- If the level of cash inflow into a region is larger than the fraction of notes in circulation (e.g., as a result of the particular cash cycle model implemented in the region), then the value of $a_{t i}$ is corrected in an appropriate way: in plus if the inflow is lower or in minus if the inflow is greater than circulation.

- The proportion $k_{i}(t)$ is not dependent on cash in circulation in Poland or on the level of total cash inflow to the central bank.

In general, formula (4) allows one to take into account not only the distribution of circulation among regions, but also the distribution of returned notes to the Bank. In the case of different cash cycle models in regions and/or various public habits on cash usage, this feature is essential and useful.

\section{Model of Migration}

\subsection{Mathematical Model of Migration}

During a certain period, every note can perform the following activities:

- move to another region, or

- stay in the same region.

The banknote can also be shredded because of poor quality.

However, we have limited our consideration to fit notes only. Notes can migrate because of some features of the origin and destination regions: population, GDP, tourist attractions, etc.

Such a drift can be described by a stochastic process with states as regions and transition probability as a chance of banknote movement during one step. Due 
to the weekly frequency of data collection, we define the step as one week ${ }^{2}$.

We can assume that the transition between two regions is independent of the whole history, which is suggested by the existing so-called Markov property (the independence of the future from the past) ${ }^{3}$.
Such features allow us to use the firstorder Markov chain (MC) $\left(X_{n}\right)_{n}=1, \ldots, N$ over a finite set of $r$ states, $S=\left\{s_{1}, s_{2}, \ldots, s_{r}\right\}$ as a model of fit notes migration 4 .

Figure 2 shows the geographical location of the MC states in Poland.

Figure 2. Geographical location of Markov chain states

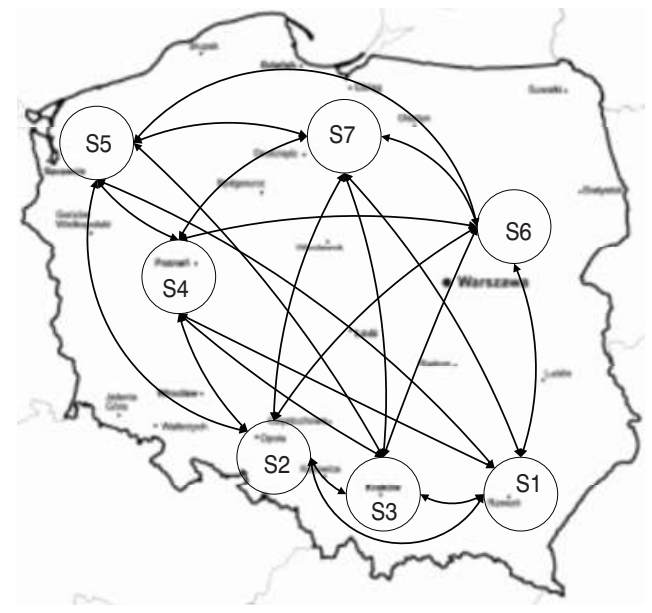

Source: Own calculation based on data collected by BPS M7 sorter machines.

In the notation of the MC, we can say that if the note is in state $s_{i}$ (the $i$-th region), then it can move to state $s_{j}$ ( $j$-th region) at the one step with a probability $p_{i j}$ called transition probability, which is not dependent on the history before state $i$ :

$$
p_{i j}(n)=P\left\{X_{n}=j / X_{n-1}=i\right\} .
$$

We assumed time-invariant transition probabilities (i.e. $\left.p_{i j}(n)=p_{i j}\right)^{5}$. Thus, we can investigate a time-homogeneous Markov chain with a square one-step transition probability matrix $\mathbf{P}$ as:

$$
\mathbf{P}=\left[\begin{array}{ccc}
p_{11} & \cdots & p_{1 r} \\
\vdots & \ddots & \vdots \\
p_{r 1} & \cdots & p_{r r}
\end{array}\right]
$$

The transition matrix $\mathbf{P}$ allows us to calculate the probability that MC (note) will be in certain states after $n$ steps:

$$
\mathbf{d}_{n}=\mathbf{d}_{0} \mathbf{P}^{n}
$$

with $\mathbf{d}_{0}$ as the probability vector which represents the starting (initial) distribution (the $i$-th element of $\mathbf{d}_{0}$ is denoted by $d_{0 i}=P\{X(0)=i\}$.

Consideration of only fit notes without their loss (e.g., destruction by consumers or migration abroad) suggests the existence of all states (regions) as transient, which means a lack of absorbing states of MC.

The exclusion of absorbing states (as a model of shredding unfit notes) is caused by the following two reasons:

- We would like to know if and when the process of migration can reach a stable state;

- Consideration of the absorbing states could disturb the time-homogeneity property. Namely, according to another of our studies, the lifetime of notes as a random variable is not memoryless in contrast to a variable with exponential or geometric distribution. 
In the analysis of note migration in the long term, the stationarity and ergodicity of $\mathrm{MC}$ can be interesting:

The second kind of MC is very interesting. In the case of the ergodic property of MC, the limit of $\mathbf{P}^{n}$ exists (Frechet theorem) (see, for example, Privault, 2018):

$$
\lim _{n \rightarrow \infty} \mathbf{P}^{n}=\mathbf{E} .
$$

The existing stochastic ergodic matrix $\mathbf{E}$ (composed of identical rows e) means that there is a unique final state distribution $\mathbf{e}$ independent of start states $\mathbf{d}_{0} 6$ :

$$
\lim _{n \rightarrow \infty} \mathbf{d}_{n}=\lim _{n \rightarrow \infty} \mathbf{d}_{0} \mathbf{P}^{n}=\mathbf{d}_{0} \mathbf{E}=\mathbf{e}
$$

The above property means that the note distribution in the future is constant and is independent of where the notes were introduced into circulation at the beginning.

The existence of $\mathbf{e}$ for homogeneous $\mathrm{MC}$ is related to some features of the transition matrix $\mathbf{P}$, which should be regular: irreducible, aperiodic, and positive recurrent. The regularity of $\mathbf{P}$ may be proven by the following eigenvalues: $\mathbf{P}$ is regular if it has a unique eigenvalue equal to 1 and other eigenvalues with a norm value below 1 .

The transition matrix allows us to calculate some characteristics of cash migration such as:

- expected number of steps to reach state $j$ from state $I$, named Mean First Passage Time (MFPT);

- expected number of steps to reach the same state named Mean Recurrence Time (MRT).

The essential role in the calculation of mean time is played by the so-called fundamental matrix, calculated according to the following formula:

$$
\mathbf{Z}=(\mathbf{I}-\mathbf{P}+\mathbf{E})
$$

$$
P\left\{X_{t}=j\right\}=\sum_{i \in \mathrm{S}} P\left\{X_{t-1}=i\right\} \cdot P\left\{X_{t}=j / X_{t-1}=i\right\}
$$

or

$$
d_{t j}=\sum_{i \in \mathrm{S}} d_{t-1 i} \cdot p_{i j}
$$

where $d_{t j}$ means a fraction (proportion) of items (notes) located in the $j$-th state (region) at time $t$ and can be estimated by $k_{j}(t)$ defined in (4).
The entry $z_{i j}$ of $\mathbf{Z}$ and ergodic distribution e can be used for calculation of the above-mentioned times according to the following formulas:

- Mean First Passage Time as (see Privault, 2018, pp. 126-127):

$$
m_{i j}=\left\{\begin{array}{cc}
\frac{z_{j j}-z_{i j}}{e_{j}} & \text { for } i \neq j \\
0 & \text { for } i=j
\end{array}\right.
$$

- Mean Recurrence Time as:

$$
\tau_{i}=\frac{1}{e_{i}}
$$

\subsection{Method of Estimation of Migration Model}

The main problem with MC estimation pertains to transition probabilities. The estimation of them is relatively simple when individual movements are observed over time (the case of micro-data). However, if the time series of observations is sufficiently long, it is possible to estimate the transition matrix from aggregate (macro) data using the Generalized Least Square (GLS) technique.

Despite having micro- (individual) data on the serial number of test notes returned to the NBP, we decided to use macro-data. The reason for such a decision is the natural incompleteness of micro-data. We observe that only some notes return to the central bank because the weekly value of the return rate is well below the level of 1 (as a result of the cash cycle model implemented by the market).

The use of macro-data is related to the implementation of the GLS method described below in detail.

According to Lee, Judge, and Zellner (1970), the estimation of transition probabilities relies on the use of the following relation:

Therefore, we have $r$ econometric models with unknown transition probability $\mathbf{P}$ :

$$
k_{j}(t)=\sum_{i \in S} k_{i}(t-1) \cdot p_{i j}+\varepsilon_{t}
$$

with restrictions due to the interpretation of $\mathbf{P}$ as a probability: 


$$
\begin{gathered}
\sum_{j \in \mathrm{S}} p_{i j}=1 \text { for } i \in \mathrm{S} \\
p_{i j} \geq 0 \text { for } i, j \in \mathrm{S} .
\end{gathered}
$$

Lee, Judge, and Zellner (1970, Chapters 1,3 ) suggest minimizing the sum of squared errors in equation (15) using Ordinary Least Squared (OLS), subject to linear constraints (Conditional Least Squares method - CLS). The OLS is equivalent to solving the quadratic programming problem. The OLS estimator is consistent, but not efficient. MacRae (1977) demonstrated how to correct for the heteroskedasticity in the error term and produce a more efficient estimator using an iterative GLS technique for calculating the matrix of transition probabilities $\mathbf{P}$. The first step in the procedure is to estimate the transition matrix and then use this to calculate a consistent estimation of the conditional covariance matrix $\Omega_{(N . r) \mathrm{x}(N . r)}$. The matrix $\Omega$ is then used to obtain a subsequent estimation of the transition probabilities, with a repetition of the procedure until convergence is reached.

Using the same idea as described above, we adopted a similar approach presented by Podgórska et al. (2002) with 2 steps:

- $1^{\text {st }}$ step - the problem of minimizing a sum of squares subject to linear constraints on the probabilities as

$$
\min _{\mathbf{P}}(\mathbf{y}-\mathbf{X P})^{T}(\mathbf{y}-\mathbf{X P})
$$

with constraints:

$$
\begin{gathered}
\sum_{j \in \mathrm{S}} p_{i j}=1 \text { for } i \in \mathrm{S} . \\
p_{i j} \geq 0 \text { for } i, j \in \mathrm{S} .
\end{gathered}
$$

where

$$
\begin{aligned}
\mathbf{y} & =\left[\begin{array}{c}
\mathbf{y}_{1} \\
\mathbf{y}_{2} \\
\vdots \\
\mathbf{y}_{r}
\end{array}\right], \mathbf{y}_{i}=\left[\begin{array}{c}
k_{i}(1) \\
k_{i}(2) \\
\vdots \\
k_{i}(N)
\end{array}\right] \\
\mathbf{X} & =\left[\begin{array}{cccc}
\mathbf{K} & \mathbf{0} & \ldots & \mathbf{0} \\
\mathbf{0} & \mathbf{K} & \ldots & \mathbf{0} \\
\vdots & \vdots & \vdots & \vdots \\
\mathbf{0} & \mathbf{0} & \ldots & \mathbf{K}
\end{array}\right] \text { with } \mathbf{K}=\left[\begin{array}{cccc}
k_{1}(0) & k_{2}(0) & \ldots & k_{r}(0) \\
k_{1}(1) & k_{2}(1) & \ldots & k_{r}(1) \\
\vdots & \vdots & \vdots & \vdots \\
k_{1}(N-1) & k_{2}(N-1) & \ldots & k_{r}(N-1)
\end{array}\right] \\
\mathbf{P} & =\left[\begin{array}{c}
\mathbf{p}_{1} \\
\mathbf{p}_{2} \\
\vdots \\
\mathbf{p}_{r}
\end{array}\right] \text { with } \mathbf{p}_{i}=\left[\begin{array}{c}
p_{1 i} \\
p_{2 i} \\
\vdots \\
p_{r i}
\end{array}\right] .
\end{aligned}
$$

- $2^{\text {nd }}$ step - the problem of minimizing a sum of squares subject to linear constraints on the probabilities as

$$
\min _{\mathbf{P}}\left(\mathbf{y}^{*}-\mathbf{X}^{*} \mathbf{P}^{*}\right)^{T}\left(\Omega^{*}\right)^{-1}\left(\mathbf{y}^{*}-\mathbf{X}^{*} \mathbf{P}^{*}\right)
$$

with constraints:

$$
\begin{aligned}
& \sum_{j \in \mathrm{S} \backslash\{r\}} p_{i j} \leq 1 \text { for } i \in \mathrm{S} . \\
& p_{i j} \geq 0 \text { for } i \in \mathrm{S}, j \in \mathrm{S} \backslash\{r\}
\end{aligned}
$$


where

$$
\begin{aligned}
& \mathbf{y}^{*}=\left[\begin{array}{c}
\mathbf{y}_{1} \\
\mathbf{y}_{2} \\
\vdots \\
\mathbf{y}_{r-1}
\end{array}\right], \mathbf{X}^{*}=\left[\begin{array}{cccc}
\mathbf{K} & \mathbf{0} & \ldots & \mathbf{0} \\
\mathbf{0} & \mathbf{K} & \ldots & \mathbf{0} \\
\vdots & \vdots & \vdots & \vdots \\
\mathbf{0} & \mathbf{0} & \ldots & \mathbf{K}
\end{array}\right]_{(r-1) x r(r-1)} \quad, \mathbf{P}^{*}=\left[\begin{array}{c}
\mathbf{p}_{1} \\
\mathbf{p}_{2} \\
\vdots \\
\mathbf{p}_{r-1}
\end{array}\right] \\
& \mathbf{\Omega}^{*}=\left[\begin{array}{cccc}
\boldsymbol{\Omega}_{11} & \boldsymbol{\Omega}_{12} & \ldots & \boldsymbol{\Omega}_{1(r-1)} \\
\boldsymbol{\Omega}_{21} & \mathbf{\Omega}_{22} & \ldots & \boldsymbol{\Omega}_{2(r-1)} \\
\vdots & \vdots & \vdots & \vdots \\
\boldsymbol{\Omega}_{(r-1) 1} & \boldsymbol{\Omega}_{(r-1) 2} & \ldots & \boldsymbol{\Omega}_{(r-1)(r-1)}
\end{array}\right]_{(r-1) x N(r-1)}
\end{aligned}
$$

As we can see, the asterisk ' $*$ ' means limitation in the analysis in the states $r-1$ due to the singularity of the variancecovariance matrix $\Omega$ of the residuals for model (18).

Submatrix $\Omega_{i j}$ is estimated at the end of the $1^{\text {st }}$ step using the residuals of model (18):

$$
\boldsymbol{\Omega}_{i j}=\frac{1}{N-r} \mathbf{e}_{i}^{T} \mathbf{e}_{j} \cdot \mathbf{I}_{N \times N}
$$

with $\mathbf{e}_{j}$ as a residual of the $j$-th part of model (18).

It is worth noting that Kalbfleisch and Lawless (1984) show how to estimate transition probabilities in the case of the change of an individual population over time.

Kelton and Kelton (1984) provided test statistics that can be used to test the stationarity of the transition probabilities.

\subsection{The Gravity Model}

The banknotes are considered here as good, so their migration is strictly related to, inter alia, the movement of people (commuting to work, business trips, etc.). Thus, the gravity-like properties of cash migration point to the gravity model as one of the most pervasive empirical models in regional science. The gravity model resembles Newton's law of gravity of 1687 and is widely used by academics and policy advisors (Ramos, 2016). The most commonly applied form of the model in the case of population migration is as follows (e.g. Poot, Alimi, Cameron, \& Maré, 2016):

$$
F_{i j}=G \frac{P_{i}^{\alpha} P_{j}^{\beta}}{D_{i j}^{\gamma}}
$$

where $F_{i j}$ represents the scale of migration from the $i$-th to the $j$-th area, $P_{i}, P_{j}$ the population in areas, $D_{i j}$ - the distance between the $i$-th and the $j$-th area, $\alpha, \beta, \gamma-$ unknown parameters, $G$ - the proportionality constant which dependents on the geography, time dimension, etc.

As you can see, the model assumes existing flows between two regions: origin $i$ and destination $j$, which are directly proportional to their size, the gravitational 'mass' (e.g. population, GDP, area) and are inversely proportional to the distance between them.

We decided to choose the following independent variables: the GDP of regions as a gravitational mass (because of the transaction denomination of 10 zlotys) and physical distances between regions. The transition probabilities of the Markov chain express the attractive force between source and destination regions, so we decided to choose them as a dependent variable.

In the case of our analysis, the model specification in the simple log-log version suitable for estimation by the OLS method is as follows:

$$
\begin{gathered}
\ln p_{i j}=\beta_{0}+\beta_{1} \cdot \ln \left(G D P_{i} / G D P_{j}\right)+\beta_{2} \cdot \ln \left(\text { distance }_{i j a v e}\right)+\beta_{3} \cdot \ln \left(\text { distance }_{i j \min }\right)+ \\
+\beta_{4} \cdot \text { border }_{i j}+\varepsilon_{i j}
\end{gathered}
$$

where distance $_{\text {ijave }}$ means the average distance between the capitals of voivodships included in the regions, distance $_{i j m i n}$ denotes the minimum distance between the capitals of voivodships included in the regions, border $_{i j}$ - dummy variable equals 1 
if the $i$-th and $j$-th regions share a contiguous border, $\varepsilon_{i j}$ denotes a random error term. Parameter $\beta_{0}$ refers to a gravitational constant.

\section{Results}

\subsection{Markov Chain Model}

The calculations presented below were performed on weekly data collected during
$N=158$ weeks and for $r=7$ regions (MC states).

The GLS technique described in Section 3 allows us to obtain consistent, unbiased, and the most efficient estimators of the transition probabilities $p_{i j}$ of the Markov chain based on the macro data presented in Section 2. The results of the estimation are presented in Table 27.

Table 2. Transition matrix $\boldsymbol{P}$

\begin{tabular}{|c|c|c|c|c|c|c|c|}
\hline & S-E & S-W & S & W & $\mathrm{N}-\mathrm{W}$ & E-C & $\mathrm{N}-\mathrm{C}$ \\
\hline S-E & 0.883 & 0.017 & 0 & 0.04 & 0 & 0.053 & 0.006 \\
\hline S-W & 0.028 & 0.957 & 0 & 0 & 0 & 0.015 & 0 \\
\hline$S$ & 0.007 & 0.034 & 0.959 & 0 & 0 & 0 & 0 \\
\hline W & 0 & 0.004 & 0.004 & 0.969 & 0 & 0.014 & 0.008 \\
\hline $\mathrm{N}-\mathrm{W}$ & 0 & 0 & 0 & 0 & 0.972 & 0 & 0.028 \\
\hline E-C & 0.008 & 0.005 & 0 & 0 & 0.012 & 0.968 & 0.008 \\
\hline $\mathrm{N}-\mathrm{C}$ & 0.023 & 0 & 0.013 & 0 & 0 & 0 & 0.965 \\
\hline
\end{tabular}

Explanation: The titles of columns and rows include the names of regions; see Figure 1.

Source: Own calculation based on data collected by BPS M7 sorter machines ( $N=158$ weeks, $r=7$ regions).

Based on the $p_{i j}$ estimation, we can calculate the state distribution $\mathbf{d}_{\mathbf{n}}$ separately for each region and compare it with the real proportions of notes in the regions. For this purpose, we used two types of goodness-of-fit measures: coefficient of determination $\mathrm{R}^{2}$ and the Theil coefficient. Both were assessed in two variants depending on how the state distributions $\mathbf{d}_{\mathbf{n}}, n=1$, $\ldots, N$, were estimated (forecasted).

The first case, named static, assumes the estimation of $\mathbf{d}_{\mathbf{n}}$ as a one-step ahead fore- cast using in (14) the actual value of the lagged $\mathbf{d}_{\mathbf{n}-\mathbf{1}}$.

The second case, named dynamic, assumes $\mathbf{d}_{\mathbf{n}}$ estimation as a multi-step forecast using in (14) the previously forecasted values $\mathbf{d}_{\mathbf{n}-\mathbf{1}}$, for $n=3, \ldots, N$. The state distribution at $n=2$ is estimated according to a static methodology.

The values of the two coefficients in the two variants are presented in Tables 3 (static) and 4 (dynamic).

Table 3. $R^{2}$ and Theil coefficients in the static version of $\boldsymbol{d}_{\boldsymbol{n}}$ calculation

\begin{tabular}{|c|c|c|c|c|c|c|c|c|}
\hline & $R^{2}$ & Theil & $s_{r}$ & $s_{p}$ & $r$ & $I_{1}$ & $I_{2}$ & $I_{3}$ \\
\hline S-E & 0.9995 & 0.0000 & 0.0207 & 0.0207 & 0.9997 & 0.0021 & 0.0001 & 0.9978 \\
\hline S-W & 0.9999 & 0.0000 & 0.0338 & 0.0338 & 0.9999 & 0.0005 & 0.0001 & 0.9995 \\
\hline$S$ & 0.9998 & 0.0000 & 0.0196 & 0.0196 & 0.9999 & 0.0016 & 0.0042 & 0.9942 \\
\hline W & 0.9996 & 0.0001 & 0.0863 & 0.0863 & 0.9998 & 0.0000 & 0.0000 & 1.0000 \\
\hline N-W & 0.9993 & 0.0000 & 0.0257 & 0.0256 & 0.9997 & 0.0002 & 0.0280 & 0.9719 \\
\hline E-C & 0.9996 & 0.0000 & 0.0550 & 0.0550 & 0.9998 & 0.0002 & 0.0007 & 0.9990 \\
\hline $\mathrm{N}-\mathrm{C}$ & 0.9999 & 0.0000 & 0.0447 & 0.0447 & 0.9999 & 0.0012 & 0.0001 & 0.9987 \\
\hline
\end{tabular}

Source: Own calculation based on data collected by BPS M7 sorter machines ( $N=158$ weeks, $r=7$ regions). 
Table 4. $R^{2}$ and Theil coefficients in the dynamic version of $\boldsymbol{d}_{\boldsymbol{n}}$ calculation

\begin{tabular}{l|c|c|c|c|c|c|c|c|}
\multicolumn{1}{c}{} & \multicolumn{1}{c}{$R^{2}$} & \multicolumn{1}{c}{ Theil } & $s_{r}$ & $s_{p}$ & \multicolumn{1}{c}{$r$} & $I_{1}$ & $I_{2}$ & $I_{3}$ \\
\cline { 2 - 9 } S-E & 0.9951 & 0.0003 & 0.0207 & 0.0204 & 0.9983 & 0.2431 & 0.0660 & 0.6909 \\
\cline { 2 - 9 } S-W & 0.9948 & 0.0004 & 0.0338 & 0.0327 & 0.9986 & 0.2678 & 0.1993 & 0.5329 \\
\cline { 2 - 9 } S & 0.9780 & 0.0022 & 0.0196 & 0.0187 & 0.9913 & 0.1422 & 0.1077 & 0.7502 \\
\cline { 2 - 9 } W & 0.9915 & 0.0016 & 0.0863 & 0.0857 & 0.9958 & 0.0033 & 0.0051 & 0.9917 \\
\cline { 2 - 9 } N-W & 0.9005 & 0.0058 & 0.0257 & 0.0244 & 0.9508 & 0.0360 & 0.0263 & 0.9377 \\
\cline { 2 - 9 } E-C & 0.9697 & 0.0005 & 0.0550 & 0.0537 & 0.9926 & 0.0625 & 0.0347 & 0.9029 \\
N-C & 0.9884 & 0.0008 & 0.0447 & 0.0442 & 0.9943 & 0.0183 & 0.0124 & 0.9693 \\
\hline
\end{tabular}

Source: Own calculation based on gathered data by BPS M7 sorter machines ( $N=158$ weeks, $r=7$ regions).

Besides the two main coefficients, both tables include additional factors strictly related to the Theil coefficient:

- $s_{p}$ and $s_{r}$ - sample standard deviations of forecast and real data, respectively,

- $r$-sample correlation between forecast and real value.

The last three columns show elements of the Theil coefficient as an effect of decomposition: bias proportion $\left(I_{1}\right)$, variance proportion $\left(I_{2}\right)$, and covariance proportion $\left(I_{3}\right)$. It can be noticed that the proportions sum up to 1 . The proportions tell us why the forecasts and the real data are different. The bias proportion points out the difference between the mean of the theoretical and real values. The second proportion refers to the difference between variances. The last one measures the remaining unsystematic forecast error.

Surprisingly, good and very promising results can be seen:

- each region is characterized by $R^{2}$ with a value above 0.97 (except region N-W with a value closed to 0.9 for the dynamic version) and $I$ with a value closed to 0 ;

- the values of $s_{r}$ and $s_{p}$ are very similar;

- the value of correlation $r$ is close to 1 ;

- the proportion $I_{3}$ is the greatest among all proportions of $I$.

The worst fit is observed for the N-W region (the lowest value of $R^{2}$ and the highest value of $I$ in the dynamic version of the coefficient), which is likely the result of aggregation. Namely, the N-W region comprises two neighboring voivodships, which can disturb the Markov property.

However, the appropriate levels of coefficients, especially in the dynamic version (Table 3), prove the acceptable goodness of fit of the MC model.
It suggests that the first-order Markov chain can be used to describe the movement of fit notes properly. It is especially important in the studied case of this kind of state aggregation, which gives us some geographical regions with large areas, regions with two and more neighboring regions, and regions with two separate areas.

Consequently, the obtained results may suggest that the unobserved Markov chain with states represents small regions (voivodships, poviats, or even communes as a smaller region of voivodship) and has the property of lumpability, i.e. there is a method of state aggregation which gives us the aggregated Markov process.

For the identification of the properties of MC, the following eigenvalues $\lambda_{i}$ for the transition matrix $\mathbf{P}$ were calculated: $\lambda_{1}=1, \lambda_{2}=0.9691+0.0182 i$, $\lambda_{3}=0.9691-0.0182 i, \lambda_{4}=0.9497+0.0083 i$, $\lambda_{5}=0.9497-0.0083 i, \lambda_{6}=0.8744$. We can see 3 real and 3 complex eigenvalues. Due to the existence of the unique eigenvalue 1 and other eigenvalues with an absolute value (modulus) below $1\left(\left|\lambda_{1}\right|=1\right.$, $\left|\lambda_{2}\right|=\left|\lambda_{3}\right|=0.969,\left|\lambda_{4}\right|=\left|\lambda_{5}\right|=0.95$, $\left.\left|\lambda_{6}\right|=0.8744\right)$, matrix $\mathbf{P}$ is regular. It is the proof that the Markov chain describing note migration is ergodic.

Some elements of the $\mathbf{P}$ matrix equal 0 , which means there is no chance of note movement between some regions during one week. A more convenient form for migration analysis comprises a transition matrix after a longer period of time such as $n=4$ (after month) - Table 5 and $n=12$ (after quarter) - Table 6.

We can see nonzero elements of such $n$-step transition matrix, which confirms the ergodic properties of the Markov chain. 
Table 5. Transition matrix for 4 steps (month) $\boldsymbol{P}^{4}$

\begin{tabular}{|c|c|c|c|c|c|c|c|}
\hline & S-E & S-W & S & W & $\mathrm{N}-\mathrm{W}$ & E-C & $\mathrm{N}-\mathrm{C}$ \\
\hline S-E & 0.614 & 0.056 & 0.001 & 0.129 & 0.003 & 0.173 & 0.024 \\
\hline S-W & 0.087 & 0.843 & $3 \mathrm{E}-05$ & 0.006 & 0.001 & 0.062 & 0.002 \\
\hline S & 0.028 & 0.119 & 0.846 & 0.002 & $4 \mathrm{E}-05$ & 0.005 & 3E-04 \\
\hline W & 0.005 & 0.016 & 0.014 & 0.883 & 1E-03 & 0.053 & 0.029 \\
\hline N-W & 0.003 & 9E-05 & 0.002 & 9E-05 & 0.894 & $1 \mathrm{E}-04$ & 0.1 \\
\hline E-C & 0.027 & 0.018 & $6 \mathrm{E}-04$ & 0.002 & 0.043 & 0.879 & 0.03 \\
\hline $\mathrm{N}-\mathrm{C}$ & 0.072 & 0.004 & 0.046 & 0.005 & $5 \mathrm{E}-05$ & 0.006 & 0.867 \\
\hline
\end{tabular}

Source: Own calculation based on gathered data by BPS M7 sorter machines ( $N=158$ weeks, $r=7$ regions).

Table 6. Transition matrix for 12 steps (quarterly) $\mathbf{P}^{12}$

\begin{tabular}{|c|c|c|c|c|c|c|c|}
\hline & S-E & S-W & S & W & $\mathrm{N}-\mathrm{W}$ & E-C & $\mathrm{N}-\mathrm{C}$ \\
\hline S-E & 0.258 & 0.104 & 0.009 & 0.222 & 0.025 & 0.32 & 0.063 \\
\hline S-W & 0.145 & 0.614 & 0.001 & 0.04 & 0.011 & 0.175 & 0.015 \\
\hline S & 0.07 & 0.259 & 0.606 & 0.015 & 0.002 & 0.044 & 0.004 \\
\hline W & 0.022 & 0.044 & 0.035 & 0.691 & 0.009 & 0.13 & 0.071 \\
\hline $\mathrm{N}-\mathrm{W}$ & 0.023 & 0.003 & 0.017 & 0.003 & 0.715 & 0.005 & 0.234 \\
\hline E-C & 0.055 & 0.045 & 0.006 & 0.013 & 0.103 & 0.695 & 0.083 \\
\hline $\mathrm{N}-\mathrm{C}$ & 0.125 & 0.034 & 0.102 & 0.033 & 0.002 & 0.047 & 0.656 \\
\hline
\end{tabular}

Source: Own calculation based on gathered data by BPS M7 sorter machines ( $N=158$ weeks, $r=7$ regions).

The comparison of the probability $p_{i i}^{(n)}$ ing. The sets of probabilities for $n=1,4$ that the note will remain in the same state $i$ and 12 are presented in Table 7. during some period of time is very interest-

Table 7. The $n$-step transition probabilities $p_{i i}^{(n)}=P\{X(n)=i / X(0)=i\}$

\begin{tabular}{|c|c|c|c|c|c|c|c|}
\hline$p_{i i}^{(n)}$ & S-E & S-W & S & W & N-W & E-C & $\mathrm{N}-\mathrm{C}$ \\
\hline $\begin{array}{l}\mathrm{n}=1 \\
\text { (week) }\end{array}$ & 0.8832 & 0.9573 & 0.9591 & 0.9692 & 0.9724 & 0.9675 & 0.9646 \\
\hline $\begin{array}{l}\mathrm{n}=4 \\
\text { (month) }\end{array}$ & 0.6139 & 0.8428 & 0.8462 & 0.8826 & 0.8941 & 0.8789 & 0.8665 \\
\hline $\begin{array}{l}\mathrm{n}=12 \\
\text { (quarter) }\end{array}$ & 0.2578 & 0.6135 & 0.6062 & 0.6908 & 0.7149 & 0.6947 & 0.6564 \\
\hline
\end{tabular}

Source: Own calculation based on gathered data by BPS M7 sorter machines.

The sample interpretation refers to the region $\mathrm{E}-\mathrm{C}$ with the NBP branch located in Warsaw as one of the two sources of the introduction of test notes into circula- tion. A fit note which was at the beginning in region $\mathrm{E}-\mathrm{C}$ will be in the same region after 1 quarter with a probability of 0.6947 . Or, in other words, $69.47 \%$ of the fit notes 
introduced in Warsaw at the beginning of the project will be in the same region after 1 quarter.

The property of MC ergodicity means the existence of a unique final distribution e independent of the initial states. This distribution can be interpreted as a proportion of fit notes in the region after a long time.

In our case, the time of convergence of distribution $\mathbf{d}_{n}$ to the final distribution $\mathbf{e}$ equals 209 weeks. ${ }^{8}$

The e values obtained together with the distribution of notes between regions estimated by GDP and the cash returned to the Bank (RCF) are presented in Table 8 (for the RCF method data from the last month of the project was taken into account). We can see the expected similarity between the distributions based on e and GDP, which follows from the earlier described method of $k_{i}(t)$ estimation according to (4). The comparative analysis of the RCF distribution proves the weakness of the approach to estimating the distribution based on the flow of notes returned to the bank.

However, we should remember that the practical existence of the final distribution e requires an unrealistic assumption about the infinite lifetime of notes. However, the value of e gives us an idea of how the location of the note could stabilize across the country.

Table 8. Final-state distribution e, sharing of GDP and Return Cash Flow - RCF among the regions

\begin{tabular}{lrrrrrrc} 
& S-E & S-W & S & W & N-W & E-C & N-C \\
\hline e & $9.28 \%$ & $13.62 \%$ & $7.17 \%$ & $12.15 \%$ & $11.61 \%$ & $26.92 \%$ & $19.25 \%$ \\
GDP & $10.06 \%$ & $14.37 \%$ & $7.96 \%$ & $12.10 \%$ & $12.10 \%$ & $24.45 \%$ & $18.96 \%$ \\
RCF & $10.36 \%$ & $8.04 \%$ & $5.71 \%$ & $13.94 \%$ & $12.87 \%$ & $29.62 \%$ & $19.45 \%$ \\
\hline
\end{tabular}

Source: Own calculation based on gathered data by BPS M7 sorter machines.

The Markov chain as a model of migration allows us to estimate two kinds of mean time: the first passage and the recurrence time defined in Section 3.
For this purpose, we calculated the fundamental matrix $\mathbf{Z}$ according to formula (10). The elements of the $\mathbf{Z}$ matrix are presented in Table 9.

\section{Table 9. Fundamental matrix Z}

$\mathbf{Z}$

S-E

S-W

$\mathrm{S}$

W

$\mathrm{N}-\mathrm{W}$

E-C

$\mathrm{N}-\mathrm{C}$

\begin{tabular}{|r|r|r|r|r|r|r|}
\multicolumn{1}{c}{ S-E } & \multicolumn{1}{c}{ S-W } & \multicolumn{1}{c}{ S } & \multicolumn{1}{c}{ W } & \multicolumn{1}{c}{ N-W } & \multicolumn{1}{c|}{ E-C } & N-C \\
\hline 6.37 & -2.13 & -2.91 & 4.40 & -2.88 & 3.08 & -4.93 \\
\hline 1.41 & 17.15 & -4.56 & -2.09 & -3.72 & 1.12 & -8.30 \\
\hline 0.04 & 10.33 & 18.43 & -3.89 & -6.41 & -5.11 & -12.40 \\
\hline-2.95 & -3.57 & -1.42 & 24.66 & -5.86 & -3.85 & -6.01 \\
\hline-1.92 & -6.37 & 0.24 & -6.46 & 24.58 & -17.26 & 8.18 \\
\hline-1.45 & -4.80 & -2.83 & -5.84 & 2.38 & 15.28 & -1.74 \\
\hline 1.44 & -1.44 & 2.84 & -2.06 & -7.44 & -7.51 & 15.16 \\
\hline
\end{tabular}

Source: Own calculation based on gathered data by BPS M7 sorter machines.

The Mean First Passage Time for every Table 11 presents the second kind of time pair $(i, j)$ of regions is included in Table 10. - Mean Recurrence. 


\begin{tabular}{l|r|r|r|r|r|r|r|}
\multicolumn{1}{c}{} & \multicolumn{1}{c}{ S-E } & \multicolumn{1}{c}{ S-W } & \multicolumn{1}{c}{ S } & \multicolumn{1}{c}{ W } & \multicolumn{1}{c}{ N-W } & \multicolumn{1}{c|}{ E-C } & \multicolumn{1}{c|}{ N-C } \\
\cline { 2 - 8 } S-E & 0.00 & 141.54 & 297.68 & 166.83 & 236.58 & 45.32 & 104.36 \\
\cline { 2 - 8 } S-W & 53.42 & 0.00 & 320.70 & 220.25 & 243.87 & 52.61 & 121.88 \\
\cline { 2 - 8 } S & 68.20 & 50.06 & 0.00 & 235.03 & 267.00 & 75.74 & 143.16 \\
\cline { 2 - 8 } W & 100.45 & 152.07 & 276.87 & 0.00 & 262.32 & 71.06 & 109.98 \\
N-W & 89.33 & 172.68 & 253.69 & 256.16 & 0.00 & 120.88 & 36.23 \\
\cline { 2 - 8 } E-C & 84.28 & 161.15 & 296.56 & 251.11 & 191.27 & 0.00 & 87.78 \\
N-C & 53.10 & 136.45 & 217.45 & 219.93 & 275.92 & 84.65 & 0.00 \\
\cline { 2 - 8 } & & & & & & &
\end{tabular}

Source: Own calculation based on gathered data by BPS M7 sorter machines.

Table 11. Mean Recurrence Time $\tau_{i}$

\begin{tabular}{ccccccc} 
S-E & S-W & S & W & N-W & E-C & N-C \\
\hline 10.8 & 7.34 & 13.9 & 8.23 & 8.62 & 3.71 & 5.19 \\
\hline
\end{tabular}

Source: Own calculation based on gathered data by BPS M7 sorter machines.

We can see that the MFPT matrix is asymmetric with non-diagonal elements with values from 36.23 up to 320.7 weeks.

For example, notes migrate faster from N-W to S-E than in the opposite way. Notes located in the N-W region can be expected in the S-E region after 89.33 weeks. However, notes located in the S-E region can pass to the N-W region on average in 236.58 weeks.

For some pairs of regions (e.g. N-C and $\mathrm{E}-\mathrm{C}$, which have a long border), the movement times in both directions are similar.

The long transition time between some regions can be explained in different ways. The first reason is related to the high value of $p_{i i}$, i.e., the $i$-th region does not allow the banknote to leave its location because of its strong attractive force. However, there is a second explanation based on the use of macro-data for estimation. Such a kind of data registers the movement of notes by their number, not by individual characteristics. In other words, it is not possible to identify bilateral movements of the same number of notes between regions during a time that is shorter than one week (step) using macro- data.
We can notice unexpected short mean recurrence times for every state (expected number of steps to return to state $i$ if $\mathrm{MC}$ is started in the same state). According to the methodology of MRT estimation, when the note stays in the same region during one step, then the recurrence time is at the level of 1 . Therefore, a short MRT time for each state is caused by a high level of $p_{i i}$.

\subsection{The Gravity Model}

In our analysis, we considered two kinds of gravity models with 12-step transition variable $p_{i j}^{(12)}, i \neq j$ as a dependent variable describing the chance of a state change at 12 steps (3 months):

- Model 1 is defined at the level with the following explanatory variables: GDP of origin and destination regions, two kinds of distances between regions (as an average and minimum of distances between capitals of voivodships), and a dummy variable for pairs of regions that share a contiguous border;

- Model 2- log-log function (25).

The estimation results of model 1 are presented in Table 12 and those of model 2 in Table $13^{9}$. 
Table 12. Results of Model 1 estimation with dependent variable $p_{i j}^{(12)}, i \neq j$

\begin{tabular}{|c|c|c|c|c|}
\hline Variable & Coefficient & Std. Error & t-Statistic & Prob. \\
\hline $\mathrm{GDP}_{\mathrm{i}}$ & -0.167142 & 0.214066 & -0.780796 & 0.4399 \\
\hline $\mathrm{GDP}_{\mathrm{j}}$ & 0.409465 & 0.214066 & 1.912798 & 0.0635 \\
\hline Distance $_{\mathrm{ijAVE}}$ & $-7.83 \mathrm{E}-05$ & 0.000177 & -0.442657 & 0.6606 \\
\hline Distance $_{\mathrm{ijMIN}}$ & 0.000180 & 0.000231 & 0.777439 & 0.4418 \\
\hline BORDER $_{\mathrm{ij}}$ & 0.043839 & 0.028174 & 1.556032 & 0.1282 \\
\hline R-squared & 0.176357 & \multicolumn{2}{|c|}{ Mean dependent var } & 0.065851 \\
\hline Adjusted R-square & 0.087314 & \multicolumn{2}{|c|}{ S.D. dependent var } & 0.077525 \\
\hline S.E. of regression & 0.074063 & \multicolumn{2}{|c|}{ Akaike info criterion } & -2.256457 \\
\hline Sum squared resid & 0.202957 & \multicolumn{2}{|c|}{ Schwarz criterion } & -2.049592 \\
\hline Log likelihood & 52.38560 & \multicolumn{2}{|c|}{ Hannan-Quinn criter. } & -2.180633 \\
\hline Durbin-Watson stat & 2.403492 & & & \\
\hline
\end{tabular}

Source: Own calculation based on gathered data by BPS M7 sorter machines.

Table 13. Results of Model 2 estimation with dependent variable $\log p_{i j}^{(12)}, i \neq j$

\begin{tabular}{|c|c|c|c|c|}
\hline Variable & Coefficient & Std. Error & t-Statistic & Prob. \\
\hline $\mathrm{LOG}\left(\mathrm{GDP}_{\mathrm{i}} / \mathrm{GDP}_{\mathrm{j}}\right)$ & -0.449387 & 0.418642 & -1.073439 & 0.2900 \\
\hline LOG(Distance $\left._{\mathrm{ijAVE}}\right)$ & 0.787522 & 1.054230 & 0.747011 & 0.4598 \\
\hline LOG(Distance $\left.{ }_{\mathrm{ijMIN}}\right)$ & 0.563928 & 0.867249 & 0.650249 & 0.5195 \\
\hline BORDER $_{\mathrm{ij}}$ & 1.167449 & 0.639411 & 1.825820 & 0.0760 \\
\hline $\mathrm{C}$ & -11.56685 & 5.095931 & -2.269822 & 0.0291 \\
\hline R-squared & 0.112021 & \multicolumn{2}{|c|}{ Mean dependent var } & \\
\hline Adjusted R-squared & 0.016023 & \multicolumn{2}{|c|}{ S.D. dependent var } & \\
\hline S.E. of regression & 1.454077 & \multicolumn{2}{|c|}{ Akaike info criterion } & \\
\hline Sum squared resid & 78.23060 & \multicolumn{2}{|c|}{ Schwarz criterion } & \\
\hline Log likelihood & -72.65724 & \multirow{2}{*}{\multicolumn{2}{|c|}{ Hannan-Quinn criter. }} & \\
\hline F-statistic & 1.166915 & & Durbin-Watson stat & \\
\hline $\operatorname{Prob}($ F-statistic) & 0.341134 & & & \\
\hline
\end{tabular}

Source: Own calculation based on gathered data by BPS M7 sorter machines.

In the case of both models, we see the expected sign of the GDP parameters. The greater the GDP of the origin region and the lower the GDP of the destination region, the lower the scale of note migration. However, in Model 2 (as a log-log version of gravity model), the variable of GDP is not significant. It may mean that the migration of notes is not mainly influenced by better economic opportunities of the destination region.

In the case of both models, neighborhood makes the transition probabilities between regions higher, which may ensue from the existence of a CIT company network as well as the fact that people commute to work in neighboring regions.

Parameters for distances measured both by the average and by the minimum length have an unexpected sign (except for the average distance in Model 1). In the era of fast passenger connections and the internet that supports work from home, such results should not be surprising.

However, the R-square indicates that both models explain less than $20 \%$ of the variation of the dependent variable. 
Similar analyses (not reported here) were performed with a population size as an additional explanatory variable. The results obtained were almost identical to those of GDP: with the expected sign '-' for the origin region and ' + ' for the destination region. This means that the greater the size of the origin population and the smaller the size of the destination population, the lower the chance of migration.

\section{Conclusions}

This article is the first country study on migration of notes in Poland. Access to the data for the lowest transactional denomination has given us the possibility to investigate the specificity of note migration.

For this purpose, the Markov chain model was used. The states of MC represent the geographical location of notes, and transition probabilities describe the chance of note movement between regions. Despite the state aggregation, which gives us some large regions with two and more neighboring regions as well as one region consisting of two non-neighboring voivodships, the determination and Theil coefficients are a proof of acceptable goodness of fit of the MC model. It seems to be the most important result of our analysis.

The Markov chain, explored here as a model of note movement, offers the opportunity to estimate some factors such as:

1. mean first passage time,

2. mean recurrence time,

3. final-state distribution.

Additionally, the value of transaction probabilities of the MC allowed us to analyze the influence of some factors of the region such as GDP, population, area and border on the scale of migration.

And finally, the properties of the MC show that:

1. Movement of fit notes in Poland can be modeled by a non-absorbing Markov chain. Absorbing states could be used in a situation of fit and unfit note consideration;

2. Despite the seasonal movement of notes (e.g., summer holidays), the time-homogeneous process correctly describes the migration of notes;

3. There is a unique, final (stationary) state distribution independent of the starting state (first introduction to the circula- tion) under the assumption about the infinite life time of notes.

It is worth noting that the literature offers methods of MC consideration with the population changing over time. Such an approach could be useful in the case of changing assumptions about the same value of note shredding rates in each region (see Kalbfleisch \& Lawless, 1984).

Because of a close relation between regional demand for cash and demography of regions including the movement of people due to daily commuting to work, business trips as well as the flow of tourists, such analytical tools like Markov chain and gravity model can be adopted to analyze migration of people in Poland.

\section{Endnotes}

1 Demand for 10 -zloty banknotes is driven primarily by the transaction motive. Their role as a store of value is negligible. Additionally, the probability of their migration abroad is very low too. However, one feature of lower-denomination notes such as 10 zlotys is that they can disturb the obtained result a little - the risk of their getting lost by the public.

2 The assumption about a longer length of step could cause the impossibility of registration of bilateral movement of notes between the same regions during the one step.

3 This can be true in the case of not too large, coherent regions with only one neighbor. In the case of another region, dependencies between drift probability to the destination region and point of entry to the source region may appear. Automatically, it could disturb the Markov property. Violation of the Markov property may force us to use variable-order Markov models as an extension of the well-known Markov chain model - see Begleiter, Yaniv, and Yona (2004).

4 It is easy to prove that under the assumption about the same shredding rate in every region, the MC can be used to model the movement of fit notes.

5 The assumption seems to be invalid in the situation of, for example, seasonality. But our investigation will show the legitimacy of the adopted assumption.

6 In the case of a finite, homogenous MC, at least one marginal (stationary) distribution $\mathbf{d}$ exists: $\mathbf{d P}=\mathbf{d}$ - see Privault (2018), p. 173.

7 All calculations presented here were made on weekly data for above 3 years (158 weeks) and for 7 regions.

8 Convergence time equals the minimum of $n$ for which $\left|\mathbf{d}_{n}-\mathbf{e}\right|<1 E-4$

9 Detailed data used for estimation are presented in Appendix, Tables A.2 and A.3. 


\section{References}

Begleiter, R., El-Yaniv, R., \& Yona, G. (2004). On prediction using variable order Markov model. Journal of Artificial Intelligence Research, 22(1), 385-421.

Buchholz, P. (1994). Exact and ordinary lumpability in finite Markov chains. Journal of Applied Probability, 31(1), 59-75.

Fischer, A.M. (2014). Immigration and large banknotes. Macroeconomic Dynamics, 18(4), 899-919.

Grasland, C., Guérin, F., \& Tostain, A. (2002). The circulation of euros as a reflection of people's mobility. Population \& Societies, (384).

Kalbfleisch, J.D., \& Lawless, J.F. (1984). Leastsquares estimation of transition probabilities from aggregate data. Canadian Journal of Statistics, 12(3), 169-82.

Kelton W., David, \& Kelton, Christina M.L. (1984). Hypothesis tests for Markov process models estimated from aggregate frequency data. Journal of the American Statistical Association, 79(388), 922-928.

Lee, T.C., Judge, G.G., \& Zellner, A. (1970). Estimating the parameters of the Markov probability model from aggregate time series data. Amsterdam: North Holland.

MacRae, E.C. (1977) Estimation of time-varying Markov processes with aggregate data. Econometrica, 45(1), 183-198.

Podgórska, M., Śliwa, P., Topolewski, M., \& Wrzosek, M. (2000). Łańcuchy Markowa w teorii i w zastosowaniach. Szkoła Główna Handlowa w Warszawie.

Poot, J., Alimi, O., Cameron, M.P., \& Maré, D.C. (2016, October). The gravity model of migration: The successful comeback of an ageing superstar in regional science. IZA Discussion Paper series, (10329).

Privault, N. (2018). Understanding Markov chains. Examples and applications. Springer.

Ramos, R. (2016). Gravity models: A tool for migration analysis. Retrieved on 17 October 2021 from https://wol.iza.org/articles/gravity-modelstool-for-migration-analysis/long.

Seitz, F., Stoyan, D., \& Tödter, K.H. (2009, January). Coin migration within the euro area. Deutsche Bundesbank Discussion Paper Series 1: Economic Studies, (27).

Schautzer, A. (2006). Banknote migration in the CENTROPE region. In Proceedings of OeNB Workshops. New Regional Economics in Central European Economies: The Future of CENTROPE 9 (pp. 200-219).

Stoyan, D. (2002). Statistical analyses of euro coin mixing. Mathematical Spectrum, 35, 50-55.

Stoyan, D., Stoyan, H., \& Döge, G. (2004). Statistical analysis and modelling of the mixing process of euro coins in Germany and Europe. Australian \& New Zealand Journal of Statistics, 46(1), 67-77.

Uhl, M. (2020). Coin migration between Germany and other euro area countries. Retrieved on 17 October 2021 from https://www.bundesbank.de/ en/publications/research/discussion-papers/coinmigration-between-germany-and-other-euro-areacountries-843816.

van Blokland, P., Booth, L., Hiremath, K.R., Hochstenbach, M., Koole, G., Pop, S., ... Wirosoetisno, D. (2002). The euro diffusion project. In Proceedings of the forty-second European study group with industry (pp. 41-57). 


\section{Appendix}

Table A.1. Basic statistics of regions

\begin{tabular}{|l|c|c|}
\hline Region & Area in $\mathbf{k m}^{\mathbf{2}}$ & Population \\
\hline S-E & 54679 & 5441113 \\
\hline S-W & 21745 & 5469104 \\
\hline S & 15183 & 3410441 \\
\hline W & 43814 & 4503595 \\
\hline N-W & 42852 & 4579368 \\
\hline E-C & 55746 & 6598314 \\
\hline N-C & 78686 & 8263078 \\
\hline
\end{tabular}

Source: Statistical Office, 2021

https://stat.gov.pl/obszary-tematyczne/ludnosc/ludnosc/powierzchnia-i-ludnosc-w-przekrojuterytorialnym-w-2021-roku,7,18.html.

Table A.2. Shares of the GDP of regions in the GDP of the country (in \%)

\begin{tabular}{|l|r|}
\hline \multicolumn{1}{|c|}{ Region } & \% GDP \\
\hline S-E & 14.37 \\
\hline S-W & 7.96 \\
\hline S & 12.10 \\
\hline W & 12.10 \\
\hline N-W & 24.45 \\
\hline E-C & 18.96 \\
\hline N-C & 10.06 \\
\hline
\end{tabular}

Source: Based on data of Statistical Office.

Table A.3. Two kinds of distance between regions such as an average ( $\left.d_{i j a v e}\right)$ and minimum $\left(d_{i j m i n}\right)$ of distances between capitals of voivodships

\begin{tabular}{|c|c|c|c|c|c|c|c|c|c|c|c|c|}
\hline \multirow{2}{*}{ region } & \multicolumn{2}{|c|}{ S-E } & \multicolumn{2}{|c|}{ S-W } & \multicolumn{2}{|c|}{$S$} & \multicolumn{2}{|c|}{$\mathbf{W}$} & \multicolumn{2}{|c|}{$\mathrm{N}-\mathrm{W}$} & \multicolumn{2}{|c|}{ E-C } \\
\hline & $\mathbf{d}_{\mathrm{ijave}}$ & $d_{\mathrm{ijmin}}$ & $\mathbf{d}_{\mathrm{ijave}}$ & $\mathbf{d}_{\mathrm{ijmin}}$ & $\mathbf{d}_{\mathrm{ijave}}$ & $\mathbf{d}_{\mathrm{ijmin}}$ & $\mathbf{d}_{\mathrm{ijave}}$ & $\mathbf{d}_{\mathrm{ijmin}}$ & $\begin{array}{l}d_{\text {ijave }} \\
\text { nat }\end{array}$ & $\mathbf{d}_{\mathrm{ijmin}}$ & $d_{\text {ijave }}$ & $d_{\text {ijmin }}$ \\
\hline S-W & 261.0 & 143.3 & & & & & & & & & & \\
\hline$S$ & 172.5 & 110.5 & 124.0 & 75.5 & & & & & & & & \\
\hline W & 458.5 & 335.1 & 275.4 & 223.3 & 385.8 & 364.5 & & & & & & \\
\hline $\mathrm{N}-\mathrm{W}$ & 521.7 & 275.3 & 298.9 & 86.0 & 415.3 & 256.7 & 179.3 & 152.9 & & & & \\
\hline E-C & 260.1 & 166.8 & 385.0 & 281.7 & 359.1 & 274.5 & 440.8 & 303.3 & 491.1 & 327.9 & & \\
\hline $\mathrm{N}-\mathrm{C}$ & 379.3 & 140.0 & 352.1 & 175.8 & 396.6 & 208.6 & 277.9 & 117.7 & 335.3 & 198.9 & 267 & 129.3 \\
\hline
\end{tabular}

Source: Own calculation based on Google Maps. 